\title{
Knockdown of PTGS2 by CRISPR/ CAS9 System Designates a New Potential Gene Target for Melanoma Treatment
}

\section{OPEN ACCESS}

Edited by: Apostolos Zarros,

University of Glasgow,

United Kingdom

Reviewed by:

Ricardo Alexandre Azevedo, Federal University of São Paulo,

Spain

*Correspondence: Angela lanaro ianaro@unina.it

Specialty section: This article was submitted to Experimental Pharmacology and Drug Discovery,

a section of the journal

Frontiers in Pharmacology

Received: 30 July 2019 Accepted: 13 November 2019 Published: 05 December 2019

Citation:

Ercolano G, De Cicco P, Rubino V, Terrazzano G, Ruggiero G, Carriero R, Kunderfranco $P$ and lanaro $A$ (2019) Knockdown of PTGS2 by CRISPR

CAS9 System Designates a New Potential Gene Target for Melanoma Treatment.

Front. Pharmacol. 10:1456. doi: 10.3389/fphar.2019.01456

\author{
Giuseppe Ercolano ${ }^{1}$, Paola De Cicco ${ }^{2}$, Valentina Rubino ${ }^{3,4}$, Giuseppe Terrazzano ${ }^{3,4}$, \\ Giuseppina Ruggiero ${ }^{3}$, Roberta Carriero ${ }^{5}$, Paolo Kunderfranco ${ }^{5}$ and Angela lanaro ${ }^{2 *}$ \\ ${ }^{1}$ Department of Oncology UNIL CHUV and Ludwig Institute for Cancer Research Lausanne, University of Lausanne, \\ Lausanne, Switzerland, ${ }^{2}$ Department of Pharmacy, University of Naples Federico II, Naples, Italy, ${ }^{3}$ Department of \\ Translational Medical Sciences, University of Naples Federico II, Naples, Italy, ${ }^{4}$ Department of Science, University of \\ Basilicata, Potenza, Italy, ${ }^{5}$ Bioinformatic Unit, Humanitas Clinical and Research Center, Rozzano, Italy
}

CRISPR/Cas9 has become a powerful method to engineer genomes and to activate or to repress genes expression. As such, in cancer research CRISPR/Cas9 technology represents an efficient tool to dissect mechanisms of tumorigenesis and to discover novel targets for drug development. Here, we employed the CRISPR/Cas9 technology for studying the role of prostaglandin-endoperoxide synthase 2 (PTGS2) in melanoma development and progression. Melanoma is the most aggressive form of skin cancer with a median survival of less than 1 year. Although oncogene-targeted drugs and immune checkpoint inhibitors have demonstrated a significant success in improving overall survival in patients, related toxicity and emerging resistance are ongoing challenges. Gene therapy appears to be an appealing option to enhance the efficacy of currently available melanoma therapeutics leading to better patient prognosis. Several gene therapy targets have been identified and have proven to be effective against melanoma cells. Particularly, PTGS2 is frequently expressed in malignant melanomas and its expression significantly correlates with poor survival in patients. In this study we investigated on the effect of ptgs2 knockdown in B16F10 murine melanoma cells. Our results show that reduced expression of ptgs2 in melanoma cells: i) inhibits cell proliferation, migration, and invasiveness; ii) modulates immune response by impairing myeloid derived suppressor cell differentiation; iii) reduces tumor development and metastasis in vivo. Collectively, these findings indicate that ptgs2 could represent an ideal gene to be targeted to improve success rates in the development of new and highly selective drugs for melanoma treatment.

Keywords: CRISPR/CAS9, PTGS2, COX2, melanoma, cancer 


\section{INTRODUCTION}

Cutaneous melanoma is a complex genetic disease, resulting from the sequential accumulation ofmutations capable of driving transformation and, subsequently, progression of the disease (Shain et al., 2015). Oncogene-targeted drugs such as vemurafenib and dabrafenib for BRAFV600 mutated melanoma, and immune checkpoint inhibitors targeting immunomodulatory molecules such as ipilimumab, the anticytotoxic-T-lymphocyte associated protein 4 (CTLA-4), and nivolumab and pembrolizumab, the anti-programmed cell death 1 (PD-1) have completely revolutionized the treatment of advanced melanoma in recent years. All these agents have demonstrated a significant success in improving overall survival (OS) in patients with metastatic melanoma (Chapman et al., 2011; Hauschild et al., 2012; Topalian et al., 2014; Schadendorf et al., 2015; Schachter et al., 2017). However, related toxicity and emerging resistance are ongoing challenges (Winder and Viros, 2018). One advancement of overcoming resistance to immunotherapy is the use of combination therapies. Results from pre-clinical studies and clinical trials indicate that combinations of checkpoint inhibitors, either alone or combined with novel agents, may further contribute to the improvement of patient outcomes (Khair et al., 2019). An attractive option in cancer treatment is the combined of gene therapy and immunotherapy to achieve beneficial management in melanoma patients. Gene therapy appears to be an appealing option to enhance the efficacy of currently available melanoma therapeutics leading to better patient prognosis (Menezes et al., 2018). Several gene therapy targets have been identified and have proven to be effective against melanoma cells (Viola et al., 2013). However, more studies are necessary to effectively prioritize candidate therapeutic targets for melanoma treatments. Great interest is underway focusing on molecules whose mechanisms may operate within the tumor microenvironment (TME) and could be involved in immune escape and tumor evolution. For instance, cancer development and therapeutic response may relate to numerous pro-inflammatory mediators including cytokines, chemokines, growth factors, free radicals, prostaglandins (PGs), and proteolytic enzymes, which infiltrate the TME stimulating cancer cell proliferation and inhibiting their death (Todoric et al., 2016). Moreover, these factors might cause a failure of the novel anti-cancer therapies by inducing an immunosuppressive setting, which in turn leads to drug resistance (Martin et al., 2016). Particularly, increased expression of PG-endoperoxide synthase 2 (PTGS2) also known as cyclooxygenase-2 (COX-2), and its major metabolite PGE2 has been observed in many different types of cancer including melanoma (Becker et al., 2009; Wang and Dubois, 2010; Ko et al., 2017). PGE2 is the major prostanoid demonstrated to play a predominant role in promoting tumor formation, progression, and metastasis by acting directly on tumor cells and on tumor stromal cells (Nakanishi and Rosenberg, 2013). In addition, $\mathrm{PGE}_{2}$ is also responsible for inducing an immunosuppressive response within the TME by suppressing the accumulation and the activation of conventional dendritic cells while promoting the differentiation of myeloid derived suppressor cells (MDSCs) from bone marrow (BM) myeloid progenitor cells (Wang and DuBois, 2016). More recently, we have demonstrated that PTGS2 may be considered an useful diagnostic tool in defining melanoma malignancy. In fact, PTGS2 is frequently expressed in malignant melanomas and its expression significantly correlated with poor survival in patients (Denkert et al., 2001; Goulet et al., 2003; Lee et al., 2008; Panza et al., 2016). On the other hand, the expression of miR-143-3p, a transcriptional suppressor of PTGS2, inversely correlates with human melanoma progression confirming a key role for PTGS2 in malignant melanoma (Panza et al., 2018). More interestingly, it has been recently shown by our group that inhibition of PTGS2 enhances the anti-tumor activity of PD-1/ PD-L1 based immunotherapy (Botti et al., 2017). Collectively, these findings indicate that PTGS2 could represent an ideal gene to be targeted to limit the resistance to immunotherapy as well as to enhance the effectiveness of checkpoint inhibitors in melanoma treatment.

CRISPR/Cas9 [clustered regularly interspaced short palindromic repeats (CRISPR) associated nuclease 9] is a novel innovative technology to quickly perform genetic manipulations which have been used to study gene function and their role in cellular fitness (Koike-Yusa et al., 2014; Meyers et al., 2017). More recently, the employment of the CRISPR/Cas9 technology in the study of the oncogenic events occurring during tumorigenesis, has revolutionized the research in cancer biology. Most importantly, CRISPR/Cas9 models can support the initial stages of drug discovery by contributing to a new and more effective portfolio of cancer targets (Guernet and Grumolato, 2017; Behan et al., 2019). The aim of our study was to investigate the consequences of ptsg2 deletion in melanoma development and progression. To this purpose we used the CRISPR/Cas9 technology in B16F10 murine cells and demonstrated that selective ptsg2 knockdown resulted in reduced proliferation, migration, and invasion ability of melanoma cells. Furthermore, the deletion of ptsg2 impaired MDSCs differentiation in vitro and reduced tumor development and metastasis in vivo.

\section{MATERIALS AND METHODS}

\section{Cell Culture}

The murine melanoma cells B16F10 were purchased and characterized from IRCCS AOU San Martino-IST (Genova, Italy), and were cultured in Dulbecco's modified Eagle's medium (DMEM) containing 10\% fetal bovine serum (FBS), 2 $\mathrm{mmol} / \mathrm{L} \mathrm{L}$-glutamine, $100 \mu \mathrm{mol} / \mathrm{L}$ non-essential amino acids, penicillin $(100 \mathrm{U} / \mathrm{ml})$, streptomycin $(100 \mu \mathrm{g} / \mathrm{ml})$, and $1 \mathrm{mmol} / \mathrm{L}$ sodium pyruvate (all from Sigma-Aldrich, Milan, Italy). Cells were grown at $37^{\circ} \mathrm{C}$ in a humidified incubator under $5 \% \mathrm{CO} 2$.

\section{Knockdown of ptgs2 With CRISPR-Cas9}

A CRISPR knockdown kit against mouse ptgs 2 was purchased from Origene Technologies Inc. (Rockville, MD, USA). Transfections were performed as recommended by the 
manufacturer. Briefly, $3 \times 10^{5} \mathrm{~B} 16 / \mathrm{F} 10$ cells were seeded into sixwell plates and maintained for $24 \mathrm{~h}$. TransIT-X2 Transfection Reagent (Mirus Bio LLC, Madison, WI USA) was used at a final concentration of $2.4 \%$ together with a total of $2 \mu \mathrm{g}$ plasmid $(1 \mu \mathrm{g}$ gRNA or empty-plasmid control with $1 \mu \mathrm{g}$ donor) per well. TransIT-DNA complexes were made up in serum-free growth medium. Cells were maintained for $48 \mathrm{~h}$ before cells were returned to growth medium. Transfected cells were subcultured seven times before puromycin selection $(1 \mu \mathrm{g} / \mathrm{ml}$, Santa Cruz Biotechnology, CA). Selected cells (puromycin resistant) were screened for expression of $p t g s 2$ by quantitative real-time PCR (qPCR) and Western blot analysis.

\section{RNA Purification and qPCR}

Total RNA was isolated from cells by use of the TRI-Reagent (Sigma-Aldrich, Milan, Italy), according to the manufacturer's instructions, followed by spectrophotometric quantization as previously described (De Cicco et al., 2016). Final preparation of RNA was considered DNA- and protein-free if the ratio between readings at $260 / 280 \mathrm{~nm}$ was $\geq 1$.7. Isolated mRNA was reverse-transcribed by use of iScript Reverse Transcription Supermix (Bio-Rad, Milan, Italy). The quantitative real-time PCR was carried out in CFX384 real-time PCR detection system (Bio-Rad, Milan, Italy) with specific primers (mPTGS2 5' -TACCCTCCTCACATCCCTGA-3', 5' -CCTGCTTGAGTA TGTCGCAC-3') using SYBR Green master mix kit (Bio-Rad, Milan, Italy). Samples were amplified simultaneously in triplicate in one-assay run with a non-template control blank for each primer pair to control for contamination or primer dimers formation, and the ct value for each experimental group was determined. The beta actin housekeeping gene was used as an internal control to normalize the ct values, using the $2^{-\Delta \mathrm{Ct}}$ formula.

\section{Western Blotting Analysis}

Whole cell protein was extracted with ice-cold lysis buffer supplemented with protease inhibitors, as detailed previously (Panza et al., 2015). Equal amounts of proteins were resolved on $10 \%$ Tris-glycine gels and transferred onto a nitrocellulose membrane. After blocking the nonspecific binding sites, the membrane was incubated with the primary antibody (PTGS2; cod: 160126; diluted 1:600, Cayman, MI, USA) at $4^{\circ} \mathrm{C}$ overnight. The membrane was then incubated with the appropriate peroxidase-conjugated secondary antibody and the immunoreactive bands were visualized using the enhanced chemiluminescence reagents. To verify equal protein loading, the membrane was stripped and reprobed with antiGAPDH antibody.

\section{Growth Rate Analysis}

Cell growth rate was determined by MTT (3-(4,3-(4,5dimethylthiazol-2-yl)-2,5 diphenyltetrazolium bromide 5dimethylthiazol-2-yl)-2, 5-diphenyltetrazolium bromide) assay. Briefly, cells were seeded onto 96- well plates $\left(3 \times 10^{3}\right.$ cells/well $)$ and incubated for 24, 48, and $72 \mathrm{~h}$ before adding $25 \mu \mathrm{l} \mathrm{MTT}$ (Sigma-Aldrich; $5 \mathrm{mg} / \mathrm{ml}$ in saline). Cells were then incubated for an additional $3 \mathrm{~h}$ at $37^{\circ} \mathrm{C}$. After this time interval, cells were lysed and dark blue crystals were solubilized with a solution containing $50 \% \mathrm{~N}, \mathrm{~N}$-dimethyl formamide and $20 \%$ sodium dodecyl sulfate with an adjusted $\mathrm{pH}$ of 4.5 . The optical density of each well was measured with a microplate spectrophotometer (TitertekMultiskan MCC/340), equipped with a 620-nm filter.

\section{Wound Healing Assay}

Cells were seeded in 12 -well plates $\left(2 \times 10^{5}\right.$ cells/well $)$. Once the cells reached $90 \%$ confluency, a wound area was carefully created by scraping the cell monolayer with a sterile $200 \mu$ l pipette tip. After being washed three times with PBS, scratches including the flanking front lines of cells, were photographed (20-fold magnification). Subsequently, the cells were incubated at $37^{\circ} \mathrm{C}$ in $5 \% \mathrm{CO} 2$. The width of the wound area was monitored with an inverted microscope at various time points. The wound area was measured using Image J software (LASV3.8, Germany).

\section{Transwell Migration Assay}

A complementary Transwell migration assay was performed by employing a modified Boyden chamber (Corning, pore size 8 $\mu \mathrm{m}, \mathrm{NY}, \mathrm{USA})$. Briefly, the chambers were placed into a 24 -well plate and a total of $2 \times 10^{5}$ cells were placed in the upper chamber of the Transwell in serum-free medium. Six hundred microliter of DMEM medium containing 10\% FBS was added to the lower chambers to stimulate cell migration. After incubation for $24 \mathrm{~h}$ at $37^{\circ} \mathrm{C}$, the Transwell insert were removed from the plate and non-migrant cells on the upper side of the filter were detached with the use of a cotton swab. Filters were fixed with $70 \%$ ethanol and stained with $0.2 \%$ crystal violet. Cells on the undersides of the filters were observed under a microscope at a magnification of 10x. For quantification, photographs were captured from five random fields across wells, and the number of migrated cells was counted by using Image-J software.

\section{Invasion Assay}

A Transwell insert with $8 \mu \mathrm{m}$ pore size (Millipore, USA) was coated on the upper side with Matrigel (Becton Dickinson Labware, USA) for the invasion assay. Briefly, the chambers were placed into a 24 -well plate and cells $\left(2.5 \times 10^{5} / \mathrm{ml}\right)$ were plated in the upper chamber in serum-free DMEM. After the incubation period $(16 \mathrm{~h})$, the filter was removed, and nonmigrant cells on the upper side of the filter were detached with the use of a cotton swab. Filters were fixed with $4 \%$ formaldehyde for $15 \mathrm{~min}$, and cells located in the lower filter were stained with $0.1 \%$ crystal violet for $20 \mathrm{~min}$ and then washed with PBS. The filters were examined microscopically, and cellular invasion was determined by counting the number of stained cells on each filter in at least four to five randomly selected fields.

\section{Clonogenic Assay}

Cells $\left(1 \times 10^{3}\right.$ cells/well $)$ were seeded in six-well plates and were maintained in culture for 14 days. The medium was changed every 2 days. Then, cells were washed twice with PBS, fixed by $4 \%$ paraformaldehyde, and stained with $0.5 \%$ crystal violet and colonies containing more than 50 cells (established by microscopy) were counted manually. Images of the colonies were obtained using a digital camera. 


\section{ELISA}

CXCL1/KC plasma concentrations were evaluated using ELISA kits according to the manufacturer's instruction (DuoSet ELISA, R\&D systems, Minneapolis, MN, USA).

\section{Prostaglandin E2 Assay}

PGE2 concentrations was evaluated in cell culture supernatants obtained from B16/CTRL, B16/PTGS2A, and B16/SCR. Prostaglandin E2 EIA kit (Cayman Chemicals, Ann Arbor, MI)) was used according to the manufacturer's instruction.

\section{Preparation of Melanoma Cells Conditioned Medium}

Wild-type B16/F10 (B16/CTRL) or ptgs2 knocked-down B16F10 (B16/PTGS2A) or empty-plasmid control B16F10 (B16/SCR) melanoma cells ( $80 \%$ confluence) were growth with DMEM $10 \%$ FBS in a $100-\mathrm{mm}$ diameter dish. After $24 \mathrm{~h}$, the medium was changed. The medium was collected after $48 \mathrm{~h}$, centrifuged at $1,800 \mathrm{rpm}$ for $10 \mathrm{~min}$, and filtered through a $0.22-\mu \mathrm{m}$ syringe filter.

\section{Ex Vivo Generation of MDSCs}

Bone marrow cells were obtained from femurs and tibias of C57BL/6 mice, and the red blood cells were lysed. One million cells were seeded into 24-well plates in RPMI 1640 medium supplemented with $10 \% \mathrm{FBS}, 10 \mathrm{ng} / \mathrm{ml}$ GM-CSF, $10 \mathrm{ng} / \mathrm{ml} \mathrm{IL-4,}$ and $2-\mathrm{ME}$ alone or in the presence of $30 \% \mathrm{v} / \mathrm{v}$ of B16/CTRL or B16/PTGS2 or B16/SCR conditioned medium (CM) (Youn et al., 2008). Celecoxib $(20 \mu \mathrm{M})$ was added to some wells containing $30 \% \mathrm{v} / \mathrm{v}$ of B16/CTRL CM at the beginning of the culture. The cultures were maintained at $37^{\circ} \mathrm{C}$ in $5 \% \mathrm{CO}_{2^{-}}$ humidified atmosphere. On day 3 of culture, floating cells were gently removed, and fresh medium with cytokines and the respective CM was replaced. Cells were collected on day 5 and analyzed by flow cytometry. For MDSC staining, cells were incubated with allophycocyanin-anti-CD45, FITC-anti-Ly6C, PerCP-Cy5.5-anti-CD11b, and PE-anti-Ly6G antibodies for 30' at $4^{\circ} \mathrm{C}$. Flow cytometry and data analysis were performed by using a two-laser equipped FACSCalibur apparatus and the CellQuest analysis software (Becton Dickinson, Mountain View, CA).

\section{Mice}

The experimental procedures, according to Italian (DL 26/2014) and European (n. 63/2010/UE) regulations on the protection of animals used for experimental and other scientific purposes, were approved by the Italian Ministry. All studies involving animals are reported in accordance with the ARRIVE guidelines for reporting experiments involving animals (Kilkenny et al., 2010). Mice were observed daily and humanely euthanized by $\mathrm{CO}_{2}$ inhalation if a solitary subcutaneous tumor exceeded $1.5 \mathrm{~cm}$ in diameter or mice showed signs referable to metastatic cancer. All efforts were made to minimize suffering. Female C57BL/6 mice (6 weeks old; 18-20 g) were purchased from Charles River Laboratories, Inc. Mice were housed at the Animal Research Facility of the Department of Pharmacy of the University of Naples Federico II.

\section{In Vivo Melanoma Model}

In the cutaneous melanoma tumor model, mice were subcutaneously injected in the right flank with B16/F10, B16/ PTGS2 $\Delta$, and B16/SCR cells $\left(1 \times 10^{5} / 0.1 \mathrm{ml}\right)(\mathrm{n}=8$ each group). Tumor growth was monitored every 3 days. Solid tumors formed at the site of injections were measured using a digital caliper, and tumor volume was calculated using the following equation: tumor volume $=\Pi / 6(\mathrm{D} 1 \times \mathrm{D} 2 \times \mathrm{D} 3)$ where $\mathrm{D} 1=$ length; D2 = width; D3 = height and expressed as $\mathrm{cm}^{3}$. Tumor weight was evaluated post sacrification.

For tumor metastasis experiments, mice ( $\mathrm{n}=8$ each group) were injected with B16/F10, B16/PTGS2 $\Delta$, and B16/SCR cells $\left(5 \times 10^{5} / 0.1 \mathrm{ml}\right)$ via the tail vein. After 14 days, the mice were sacrificed and the lungs were removed and washed with PBS. The lung tumors were counted and lung images were captured.

\section{Preparation of a Single Cell Suspension From Tumor}

Tumor-bearing mice were sacrificed 14 days after tumor implant and tumors were isolated. Single-cell suspensions from tumor tissue were prepared using the GentleMACS protocol (Miltenyi Biotec). Briefly, tumors were isolated and minced into small pieces followed by a mechanical dissociation step using the GentleMACS dissociator. Samples were then incubated for 40 $\mathrm{min}$ at $37^{\circ} \mathrm{C}$ with the following enzymes: collagenase I (10,000 U/ $\mathrm{ml})$ and dispase II $(32 \mathrm{mg} / \mathrm{ml})$. After a last mechanical disruption step, the digested tumors were harvested and filtered (over a 70 $\mu \mathrm{M}$ nylon filter, BD Falcon) and red blood cells were lysed by adding Tris-buffered ammonium chloride. Cells were then analyzed using flow cytometry.

\section{Flow Cytometry}

Aliquots of $5 \times 10^{5}$ cells were washed in FACS buffer (PBS, $0.1 \%$ BSA) and stained using the following panel of monoclonal antibodies (mAbs) to murine cell surface molecules (all from BD Biosciences): PerCP-Cy5.5-conjugated anti-CD11b, PEconjugated anti-Ly6G, FITC-conjugated anti-Ly6C, allophycocyanin-conjugated anti-CD45. Cells were washed in FACS buffer and data were collected using a two-laser equipped FACSCalibur apparatus and the CellQuest analysis software (Becton Dickinson, Mountain View, CA).

\section{Public Gene Expression Analysis}

Two gene expression datasets were collected and analyzed for PTGS2 expressions in human samples. The first public gene expression study came from a public microarray of normal skin and primary melanomas. Normalized gene expression, fold change, and $P$ values were retrieved from Oncomine database (Rhodes et al., 2004). For the second gene expression dataset, RNA-sequencing data of formalin fixed primary human melanoma tissue sections were retrieved from GEO (GSE126076), as un-normalized data. Each single tumor was microdissected into samples containing tumor center, tumor border, or tissue adjacent to the tumor (Shurin et al., 2019). Differential expression analysis was performed using the edgeR package (Robinson et al., 2010), applying the TMM normalization method and the glmQLFTest function. 


\section{Statistical Analysis}

Data were expressed as the mean \pm standard error of mean. Difference between groups was determined by one-way ANOVA. $P<0.05$ was considered statistically significant.

\section{RESULTS}

\section{PTGS2 Expression in Human Melanoma}

In order to investigate the correlation between PTGS2 expression and human melanoma development we performed a bioinformatics analysis of available gene expression datasets. From Oncomine database, we found that PTGS2 gene appeared to be up-regulated in primary tumors respect to normal skin (Figure 1A). To confirm this finding, PTGS2 expressions data in normal tissue, tumor mass, and tissue adjacent to the tumor were obtained from the dataset of Shurin et al. Similarly, we found that PTGS2 resulted significantly up-regulated in tumor tissues compared to normal tissues and tumor border (Figure 1B). These evidence indicate that PTGS2 has great potential to use as a biomarker and target for melanoma therapy.

\section{Generating ptgs2 Knocked-Down Melanoma Cell Line Using the CRISPR/ Cas9 System}

Next, we developed a cell line with a permanent knockdown of ptgs2 (B16/PTGS2 $\Delta$ ) by using CRISPR/Cas9 technology, in order to study the effect of ptgs 2 deletion in melanoma development and progression. B16F10 murine melanoma cells were cotransfected with guide-RNAs targeting the ptgs 2 gene or scramble negative control (SCR) together with a Cas9 and a donor construct containing the puromycin resistance gene. We chose to delete one allele to assure a knockdown rather than a complete knockout, which might have been noxious. The knockdown of ptgs 2 was verified using qPCR (Figure 2A) and confirmed at the protein level by western blotting analysis (Figure 2B). The result showed that the expression of both PTGS2 mRNA and protein was significantly decreased in B16/ PTGS2 $\Delta$ cells compared to the corresponding vector control cells (B16/SCR) and to wild-type B16F10 cells (B16/CTRL). To further validate the efficiency of PTGS2 gene knockdown in B16F10 cells, we also measured the levels of PGE2 in cell supernatants. PGE2 is a potent inflammatory mediator that is generated by PTGS2 conversion of arachidonic acid. PGE2 is considered the cardinal mediator of PTGS2-induced tumorigenesis. Indeed, it supports tumor growth by promoting angiogenesis, stimulating tumor-cell proliferation, protecting tumor cells from apoptosis, and inducing metastasis formation by upregulation of matrix metalloproteinases (MMPs) (Sinha et al., 2007). Production of $\mathrm{PGE}_{2}$ by ptgs 2 CRISPR-targeted clones was also greatly decreased (Figure 2C).

\section{Ptgs2 Knockdown Reduces Cell Proliferation and Colony Formation}

To address the role of PTGS2 in melanoma development, the potential effects of ptgs 2 knockdown on cell proliferation and colony formation were explored in B16F10 melanoma cells. The results obtained from the MTT assay demonstrated that B16/ PTGS2 $\Delta$ cells presented significantly slower proliferative rate than B16/CTRL or B16/SCR (Figure 3A). To further determine the effects of PTGS2 on cell proliferation, we performed a colony formation assay. Thus, B16/CTRL, B16/PTGS2 $\Delta$, and B16/SCR cells were seeded into six-well plates and incubated for 14 days to allow focus formation. As shown in Figures 3B, C, the focus diameter was smaller and the number of colonies were fewer in B16/PTGS2 2 group compared with B16/CTRL or B16/SCR.
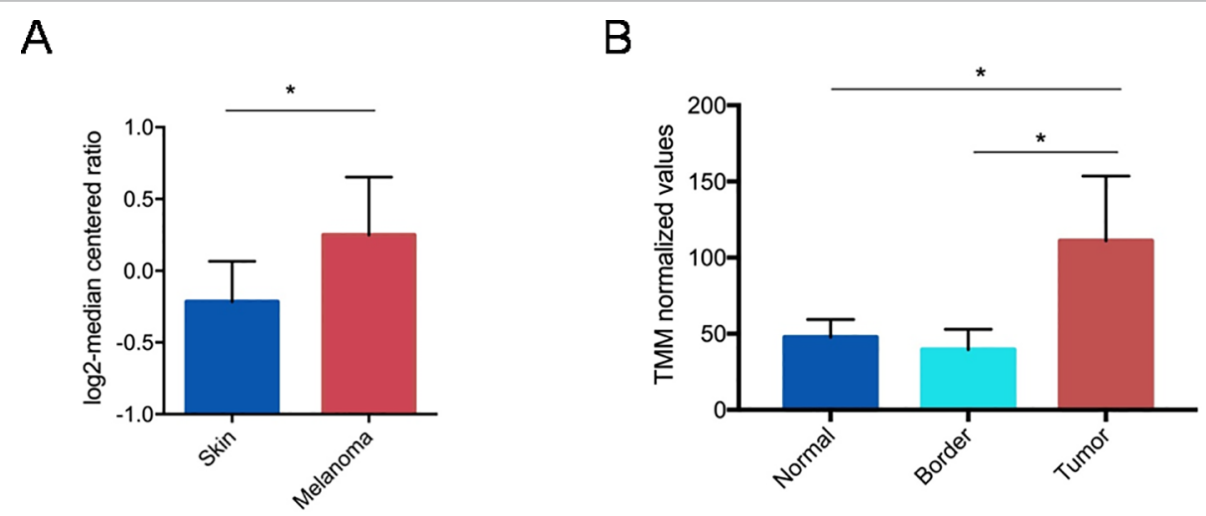

FIGURE 1 | Gene expression analysis of PTGS2 gene (R80217 probe) from Oncomine. Straight bars represent the median. The data are presented as the mean \pm SEM. PTGS2 resulted up-regulated in primary tumors respect to normal skin (fold change $=1.3 ; P=0.046$ ). $\left({ }^{\star} P<0.05\right)$ (A). Gene expression analysis of $P$ TGS2 gene retrieved from GSE126076 dataset. Straight bars represent the median. The data are presented as the mean \pm SEM. $P$ TGS2 resulted up-regulated in tumors respect to tumor borders $(\log F C=1.43 ; \mathrm{FDR}=0.014)$ and normal tissues $\left.(\log F C=1.19 ; \mathrm{FDR}=0.012) .{ }^{*} F D R<0.05\right)(\mathbf{B})$ 


\section{A}

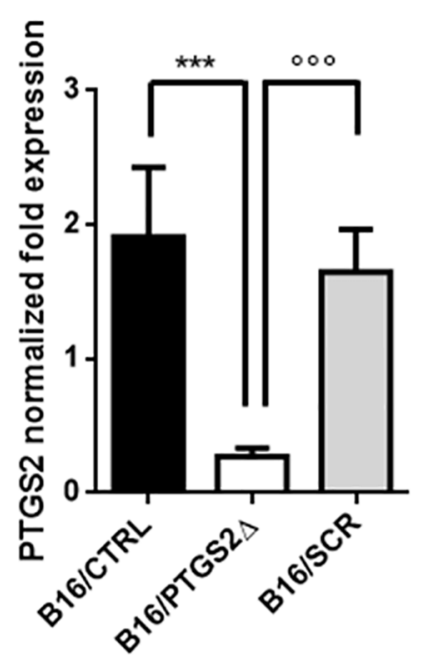

\section{C}

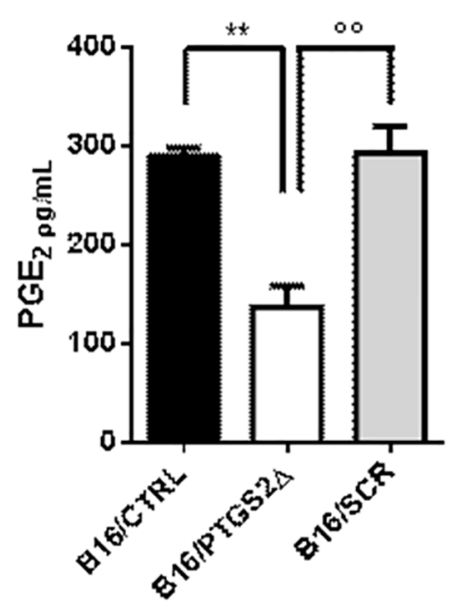

B

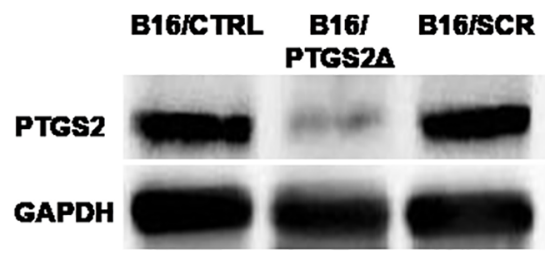

FIGURE 2 | Knockdown of PTGS2 in B16/F10 melanoma cells. B16/F10 cells were transfected with PTGS2 CRISPR/Cas9 (B16/PTGS2A), or with empty-plasmid control (B16/SCR) or not transfected (B16/CTRL). Quantitative real-time PCR (A) and western blot analysis (B) showed significant PTGS2 knockdown in B16/F10 cells. PGE2 levels were measured in cell culture supernatants by EIA. PGE2 production by B16/PTGS2 $\Delta$ was significantly reduced (C). Data are shown as mean \pm SEM of three independent experiments $\left({ }^{\star \star} P<0.01 ;{ }^{* \star \star} P<0.001 \mathrm{vs}\right.$. B16/CTRL and ${ }^{\circ 0} P<0.01 ;{ }^{\circ 00} P<0.001 \mathrm{vs}$. B16/SCR).

\section{Ptgs2 Knockdown Reduces Cell Invasion and Motility}

Local cancer cell invasion and migration represent the crucial steps in the process of metastasis formation that dramatically worsen prognosis and patient's survival (van Zijl et al., 2011). Thus, we then investigated whether the knockdown of ptgs 2 affected the motility and invasive properties of B16F10 cells. We first examined the effect on the migration of B16F10 cells in a scratch wound healing assay. Results showed that B16/PTGS2 $\Delta$ displayed lower levels of migration than B16/CTRL and B16/SCR cells (Figures 4A, B), as the wound area $24 \mathrm{~h}$ after wound generation resulted almost $35 \%$ wider. Similar results were found in the Transwell assays, which showed that B16/PTGS2 $\Delta$ cell line exhibited a reduced migratory capacity compared to B16/CTRL and B16/SCR cells (Figures 4C, D).
To evaluate cell invasion capacity, membranes were coated with Matrigel, mimicking the extracellular matrix. As show in Figures 4E, F, -B16/PTGS2 $\Delta$ cells exhibited lower rate of invasion compared to B16/CTRL and B16/SCR cells.

\section{Ptgs2 Knockdown Impairs MDSCs Differentiation In Vitro}

MDSCs facilitate tumor progression by dampening immunosurveillance and are considered an important target for tumor immunotherapy (Wesolowski et al., 2013). MDSCs are a heterogeneous population of immature myeloid cells identified as $\mathrm{CD} 11 \mathrm{~b}^{+} \mathrm{Gr}-\mathrm{1}^{+}$. Two different subtypes of MDSCs have been characterized in mice with distinct phenotypes, morphology, and immunosuppressive mechanisms, namely granulocytic MDSCs (gr-MDSCs) and monocytic MDSC (mo- 
A

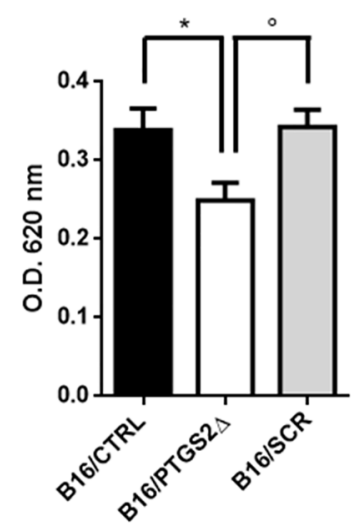

B

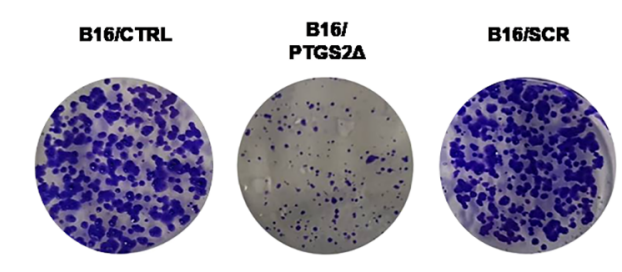

C

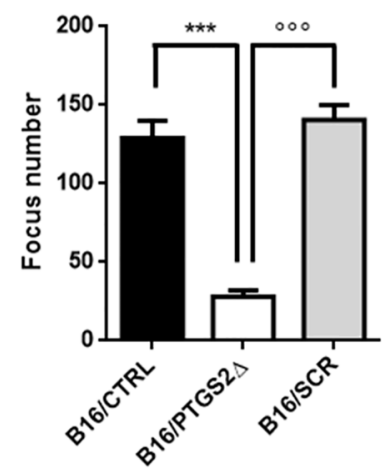

FIGURE 3 | Knockdown of PTGS2 reduces cell proliferation and clonogenicity. Cell proliferation was determined by MTT assay and is expressed as OD values. B16/PTGS2 $\Delta$ cells showed significantly slower proliferative rate than B16/CTRL or B16/SCR (A). Clonogenic assay was performed on B16/F10 cells for 2 weeks. Representative images $\mathbf{( B )}$ and relative quantification of the colonies $\mathbf{( C )}$. The number of colonies were fewer in B16/PTGS2 $\Delta$. Data are shown as mean \pm SEM of three independent experiments ( ${ }^{\star} P<0.05$ vs. B16/CTRL; ${ }^{\circ} P<0.05$ vs. B16/SCR; ${ }^{\star \star \star} P<0.001$ vs. B16/CTRL; ${ }^{\circ 00} P<0.001$ vs. B16/SCR).

MDSCs) (Youn et al., 2008). Their heterogeneity is tumor dependent and is most likely spawned from the unique inflammatory milieu existing in the TME. To investigate the effect of ptgs 2 knockdown on MDSCs differentiation, we generated MDSCs from murine BM cells by using B16F10 melanoma cells derived CM. Then, we analyzed BM-derived MDSCs using a flow cytometry scheme and markers that have been previously validated for the study of tumor-associated myeloid cells (Figure 5) (Youn et al., 2008). We found that culturing BM cells in the presence of B16/CTRL CM led to a strong myeloid differentiation in mo-MDSCs (Ly6C ${ }^{\text {hi }}, \mathrm{Ly}_{6 \mathrm{G}}^{-}$) and gr-MDSCs $\left(\right.$ Ly6C ${ }^{\text {low }}, \mathrm{Ly}_{6 \mathrm{G}}{ }^{+}$). The frequency of mo-MDSCs resulted about threefold higher compared to cells cultured with GM-CSF and IL-4 alone (basal condition) (31.91\% vs. 9.74\%, $P<$ $0.001)$. Likewise, the frequency of gr-MDSCs was almost doubled than the frequency of gr-MDSCs in basal condition (13.62\% vs. $6.59 \%, P<0.05)$. These results confirm the importance of tumor-derived factors in inducing MDSCs differentiation. Interestingly, when $\mathrm{BM}$ cells were cultured in presence of CM obtained from B16/PTGS2 $\Delta$ a significant reduction in the frequencies of both mo-MDSCs $(9.43 \%$ vs. $31.91 \%, P<0.001)$ and gr-MDSCs $(2.15 \%$ vs. $13.62 \% P<0.05)$ was observed. Indeed, the frequencies of MDSCs induced by B16/PTGS2 $\Delta$-CM was even less than the frequencies of MDSCs observed in basal condition suggesting the key role of PTGS2 in modulating the B16 derived pro-inflammatory factors triggering MDSCs differentiation. B16/SCR-CM had comparable effect of B16/CTRL-CM (Figures 5B, C). Similarly, addition of the PTGS2 selective antagonist celecoxib $(20 \mu \mathrm{M})$ to B16/CTRL-
CM significantly reduced the induction of mo-MDSCs $(19.8 \%$ vs. $33.04 \%, P<0.05)$ and gr-MDSCs $(6.91 \%$ vs. $19.8 \% P<0.05)$ from BM cells, confirming that PTGS2 mediates MDSCs differentiation (Figures 5D, E).

\section{Ptgs2 Knockdown Inhibits Subcutaneous and Metastatic Melanoma in Mice}

To evaluate the effect of ptgs 2 knockdown in vivo, we subcutaneously implanted B16/PTGS2 $\Delta$ or B16/CTRL or B16/ SCR in C57BL/6 mice. After 14 days, tumor analysis revealed that tumor volume was $30 \%$ smaller in B16/PTGS2 $\Delta$ bearing mice $(0.357 \pm 0.04 \mathrm{~cm} 3 ; P<0.05)$ compared with $B 16 / C T R L$ and B16/SCR bearing mice $(0.500 \pm 0.02 \mathrm{~cm} 3 ; 0.520 \pm 0.03 \mathrm{~cm} 3$ respectively) (Figure 6A). Tumor weight was also reduced in B16/PTGS2 $\Delta$ bearing mice by $30 \%$ ( $469 \pm 15.8 \mathrm{mg}$ mean weight; $P<0.05)$ as compared to B16/CTRL and B16/SCR bearing mice $(669 \pm 68 \mathrm{mg}$ mean weight; $589 \pm 53 \mathrm{mg}$ mean weight respectively) (Figure 6B). To verify whether tumor growth inhibition was influenced by the immune cell composition within the TME we determined the frequencies of gr-MDSCs ( C D $11 \mathrm{~b}^{+}$Ly $6 \mathrm{C}^{1 \text { ow }} \mathrm{Ly}_{6 \mathrm{G}^{+}}$) and mo-M D C s $\left(\mathrm{CD} 11 \mathrm{~b}^{+} \mathrm{Ly}_{\left.6 \mathrm{C}^{\mathrm{hi}} \mathrm{Ly} 6 \mathrm{G}^{-}\right)}\right.$subpopulations in the tumor mass of B16/CTRL, B16/PTGS2 $\Delta$, and B16/SCR-bearing mice. However, we did not find a clear difference within the groups (Figure 6C).

To deeply investigate on the role of ptgs 2 on melanoma progression, we exploited also a murine model of metastatic melanoma induced following intravenous injection of B16 cells. After 14 days we examined the lungs and we observed an impressive significant reduction of tumor foci in B16/PTGS2 $\Delta$ - 

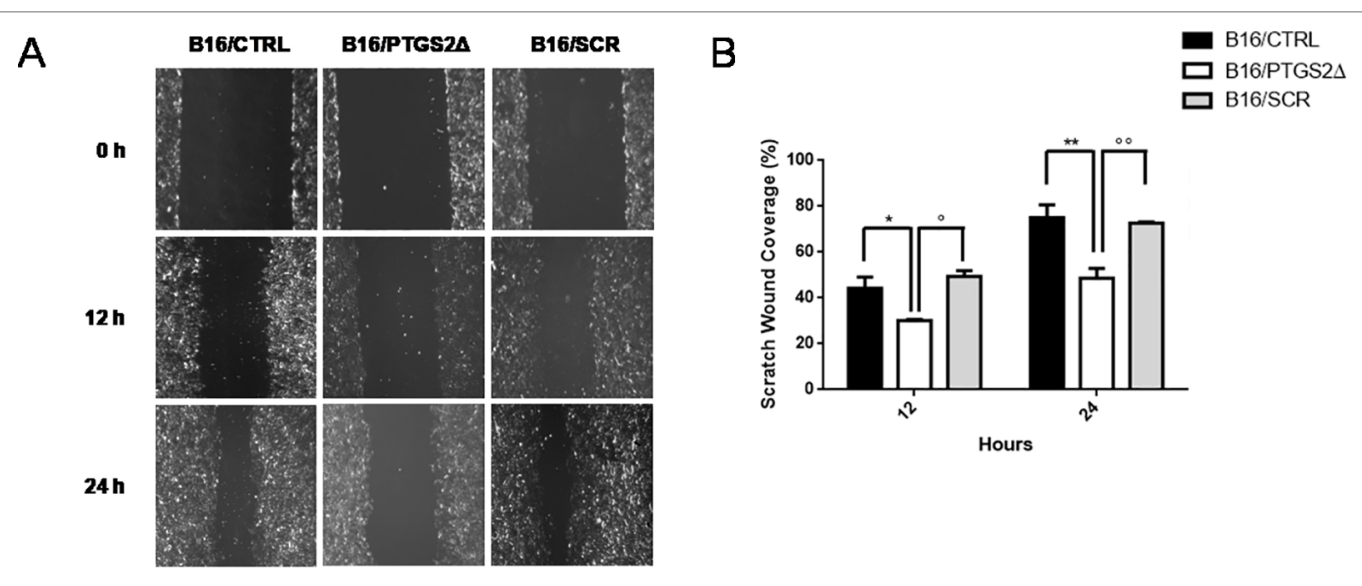

C

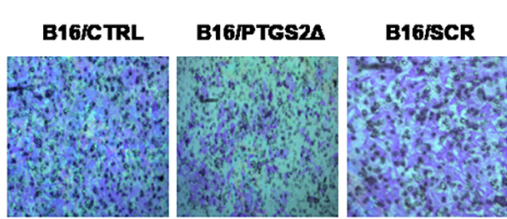

D

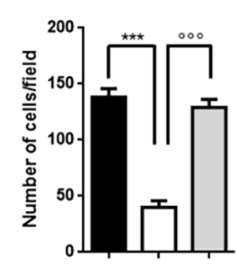

$E$

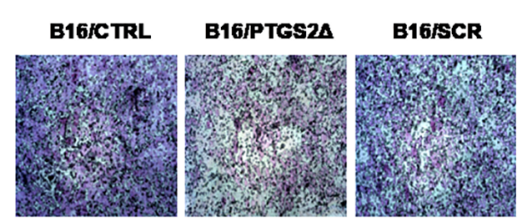

F

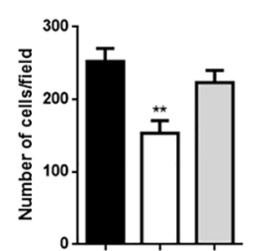

FIGURE 4 | Knockdown of PTGS2 inhibits cell migration and invasion in B16/F10 melanoma cells. The migration potential of B16/PTGS2 $\Delta$ was evaluated using the wound healing assay. Confluent B16/CTRL, B16/PTGS2A, and B16/SCR cells were wounded and allowed to migrate for 12 and $24 \mathrm{~h}$. Cells at 0, 12, and $24 \mathrm{~h}$ were imaged (A) around wounds under phase contrast microscope (10x). Quantification of the healed wound area (B) demonstrated that B16/PTGS2 $\triangle$ cells wound closure was significantly wider compared to B16/CTRL $\left({ }^{\star} P<0.05\right.$; $\left.{ }^{\star \star} P<0.01\right)$ and B16/SCR $\left({ }^{\circ} P<0.05 ;{ }^{\circ} P<0.01\right)$. The motility of B16/PTGS2 $\Delta$ was evaluated using a Transwell migration assay. Cells were seeded in the upper chamber and allowed to migrate for $24 \mathrm{~h}$; then, the migrated cells were fixed and stained with

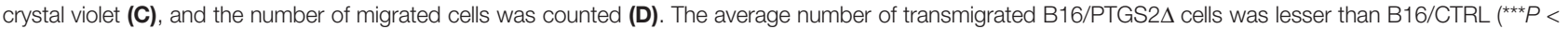
0.001 ) and $\left.B 16 / S C R{ }^{\circ 00} P<0.001\right)$. Cell invasion was determined using Boyden chambers coated with Matrigel. Representative images $(\mathbf{E})$ and relative quantification of invaded cells (F). The average number of invasive B16/PTGS2 $\Delta$ cells was significantly reduced compared to B16/CTRL ( $\left.{ }^{\star \star} P<0.01\right)$. All data are shown as mean \pm SEM of three independent experiments.

bearing mice compared with B16/CTRL and B16/SCR-bearing mice of about ten-fold (Figure 6D).

Epithelial-to-mesenchymal transition (EMT) is defined as a program in which cancer cells enhance their migratory and invasive properties in order to trigger metastasis development (Suarez-Carmona et al., 2017). Recently, different studies reported that inflammatory mediators such as cytokines, chemokines, and MMPs can promote cancer cells aggressiveness and the consequent tumor progression (Crusz and Balkwill, 2015; Pesic and Greten, 2016; Revilla et al., 2019,). In particular, CXC chemokine subfamily have been widely associated to cellular transformation, tumor growth, homing, and metastasis. Among these chemokines CXCL1 has been associated with metastatic melanoma (Dhawan and Richmond, 2002). Thus, to translate our in vitro findings of ptgs 2 knockdown-reduced migration and invasion into in vivo settings, we assessed the CXCL1 plasma levels in tumor bearing mice. As show in Figure 6E, serum levels of CXCL1 in B16/PTGS2 $\Delta$ bearing mice were significantly lower $(359 \pm 31 \mathrm{pg} /$ $\mathrm{ml}$ ) than B16/CTRL and B16/SCR bearing mice (689 $\pm 131 \mathrm{pg}$ / $\mathrm{ml} ; 568 \pm 59 \mathrm{pg} / \mathrm{ml}$ respectively). This result supports the role of PTGS2 in promoting EMT-like changes in cancer cells in order to favor tumor progression and metastasis development.

\section{DISCUSSION}

Chemotherapy, targeted therapy and immunotherapy have all been clinically utilized to target melanoma and prolong patient survival. However, most patients do not benefit from such therapies because the genetic features of patient's tumor influence clinical responses (Garraway, 2013). Thus, the requirement for personalized treatment regimens becomes mandatory (Verma, 2012). Recently, the CRISPR/Cas9 
A

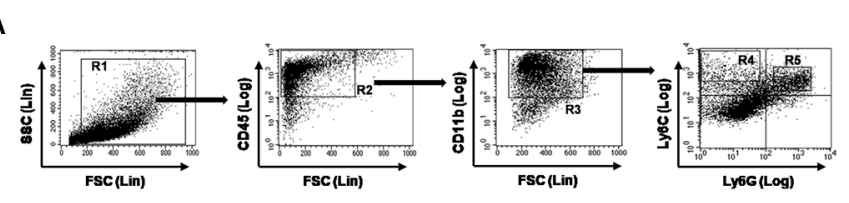

B
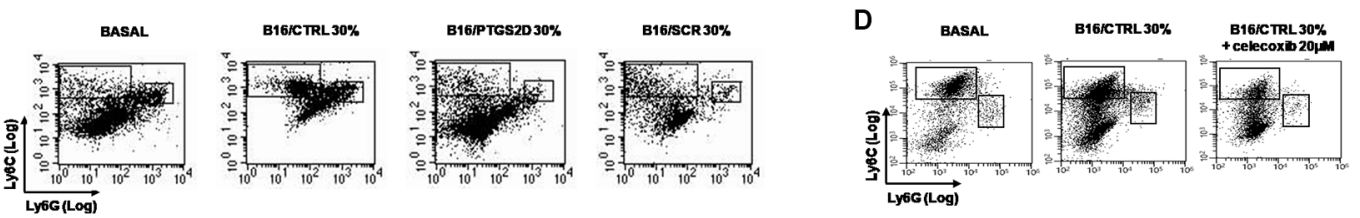

C

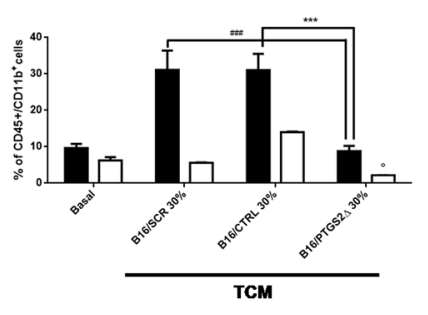

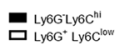

E

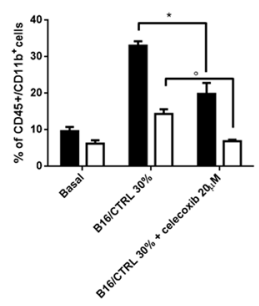

FIGURE 5 | Knockdown of PTGS2 impairs MDSCs differentiation in vitro. Wild type bone marrow cells were cultured with GM-CSF and IL-4 alone (BASAL) or with $30 \%$ tumor-conditioned medium (TCM) from B16/F10, B16/PTGS2L, and B16/SCR cells for 5 days. The surface expression of Ly6G and Ly6C was measured on gated $\mathrm{CD} 45^{+} \mathrm{Cd} 11 \mathrm{~b}^{+}$cells by flow cytometry (A). Representative flow cytometry plot (B) and relative quantification (C) of the two MDSCs subpopulations (R4: Ly6C hiLy6G-; R5: Ly6C ${ }^{\text {low }}$ Ly6G $^{+}$) obtained after stimulation with different TCM. The frequencies of both MDSCs subsets induced by B16/PTGS2 $\Delta$-CM was lesser than the frequencies of MDSCs observed with B16/F10-CM and B16/SCR-CM $\left({ }^{\circ} P<0.05\right.$ vs. B16/CTRL $30 \%$; ${ }^{* \star *} P<0.001$ vs. B16/CTRL 30\%; \#\#\# $P<0.001$ vs.

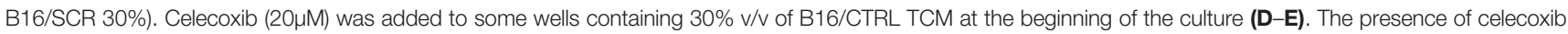
inhibited MDSCs differentiation ( ${ }^{*} P<0.05 ;{ }^{\circ} P<0.05$ vs. B16/CTRL). Data are shown as mean \pm SEM of three independent experiments
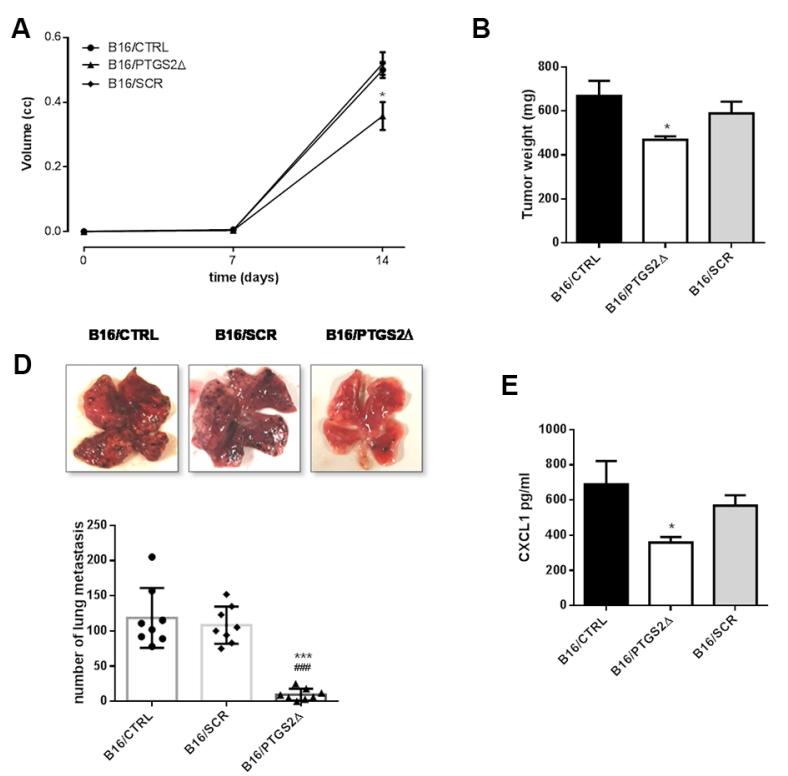

E

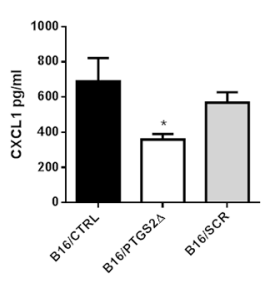

\section{C}

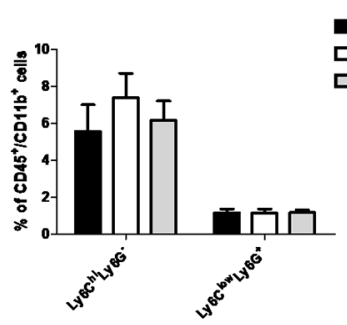

B16/CTRL B16/PTGS2 $\square$ B16/SCR

FIGURE 6 | Knockdown of PTGS2 inhibits subcutaneous and metastatic melanoma in vivo. B16/F10 (-), B16/PTGS2 (A) or B16/SCR ( $\bullet$ ) were subcutaneously implanted in mice. Tumor volume was monitored on the indicated days. The average of tumor volume and tumor weight with SEM is showed respectively in panel (A and B). Tumor volume and weight were reduced in B16/PTGS2 $\Delta$ bearing mice as compared to B16/CTRL and B16/SCR bearing mice ( ${ }^{\star} P<0.05, \mathrm{n}=8$; day 14$)$.

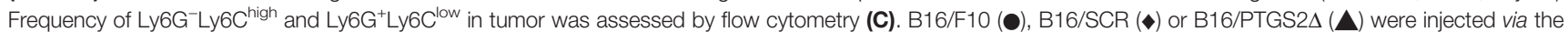
tail vein in mice. Representative macroscopic pictures of mouse lungs, 14 days after inoculation and quantification of the number of metastasis (D). The number of

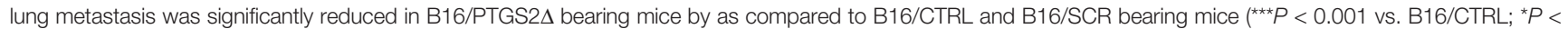
0.001 vs. B16/SCR, $n=8$; day 14). CXCL1 plasma levels $(E)$ were significantly reduced in B16/PTGS2 $\Delta$ bearing mice as compared to B16/CTRL bearing mice (\#\#\# $<0.05$ vs. B16/CTRL, $n=8$; day 14). All data are shown as mean \pm SEM. 
technology has been successfully employed to study gene functions and their role in tumors (Guernet and Grumolato, 2017). In addition, the ability of CRISPR/Cas9 to accurately and efficiently edit genes, not only in cell culture models but also in humans, allows its use as a potentially powerful therapeutic tool in cancer therapy (Martinez-Lage et al., 2018). In 2016, the first clinical trial using CRISPR technology received approval in the United States. This phase I study entitled "Phase I Trial of Autologous T Cells Engineered to Express NY-ESO-1 TCR and Gene Edited to Eliminate Endogenous TCR and PD-1" involves 18 patients with refractory tumors, including melanoma $(n=6)$, synovial sarcoma $(n=6)$, and multiple myeloma $(n=6)$, without effective therapies. The primary endpoint of this trial was to assess the safety and dosage of a novel intervention, as well as the efficacy (https://clinicaltrials.gov/ct2/show/NCT03399448).

Several different gene targets have been identified and proven to be effective against melanoma. Targeting and/or modulating the stromal TME is one strategy to treat melanoma (RomaRodrigues et al., 2019). Inflammation underlies this microenvironment and it is considered the strongest supporter in tumorigenesis. Among the different mediators of inflammation, PTGS2 clearly appear to be implicated in cancer progression, by stimulating cell proliferation, cell invasion, inducing vessel formation, and enhancing metastasis and immunosuppression (Sobolewski et al., 2010). Overexpression of PTGS2 has been detected in most types of cancer, including adenocarcinoma, hepatocellular carcinoma, colorectal cancer, breast cancer, pancreatic cancer, and lung cancers (Hashemi Goradel et al., 2019). In the present study, analyzing different gene expression datasets, we demonstrated that PTGS2 is predominately expressed in melanoma tissue while its expression is negligible in normal skin. Previously, we have also demonstrated that PTGS2 level correlates with invasiveness and poor prognosis in melanoma patients (Panza et al., 2016). Both observations indicate that PTGS2 participates in the progression of melanoma. Within the last years, potential therapeutic application of several micro-RNA (miR) that directly regulate PTGS2 expression have been reported in several cancer. We found that miR-143-3p works as tumor suppressor in malignant melanoma. Therefore, decreased levels of miR-143$3 \mathrm{p}$ in primary human melanoma lesions and metastases contributes to the up-regulation and overexpression of PTGS2 in melanoma (Panza et al., 2018). Remarkably, full deletion of ptgs 2 in knockout mice markedly reduces melanoma growth (Panza et al., 2016). The evident close association between PTGS2 gene expression and melanoma tumorigenesis (Denkert et al., 2001; Goulet et al., 2003; Lee et al., 2008; Panza et al., 2016; Kim et al., 2019,) pinpoint to PTGS2 as a potential target gene. CRISPR/Cas9-based knockout strategies are increasingly used to analyze gene function. In this study, we used the above technology to further explored the role of PTGS2 in melanoma development and progression. We conducted CRISPR/Cas9 gene-editing strategy to disrupt ptgs 2 gene sequence and eliminate PTGS2 protein expression in B16F10 murine melanoma cells. Ptgs 2 knockdown by CRISPR/Cas9 significantly inhibited cell proliferation as well as migration, invasion, and colony formation of B16F10 melanoma cells. Indeed, when we moved to in vivo melanoma models, we found that the absence of ptgs 2 in B16F10 cells dramatically reduces subcutaneous melanoma tumors as well as melanoma metastasis in mice.

PTGS2 is able to induce immune cell recruitment into the tumor tissue to promote an immunosuppressive state in the TME in favor of cancer cell activation (Obermajer et al., 2011). In fact, PTGS2/PGE2 released from cancer cells to this milieu suppresses host immunological responses to tumor-derived antigens by inducing accumulation of immunosuppressive cells like MDSCs (Sinha et al., 2007). MDSCs are the major component of immune infiltrates in tumors that negatively regulate the anti-tumor immune responses (Gabrilovich and Nagaraj, 2009). Immature MDSCs are generated from BM cells and then they expand and migrate to the TME where a complex milieu of tumor- or stromal-derived factors including vascular endothelial growth factor, IL-6, IL-1 $\beta$, GM-CSF, transforming growth factor $\beta$ as well as PGE2 modulate their suppressive function (Bunt et al., 2006; Ezernitchi et al., 2006; Bunt et al., 2007; Sinha et al., 2007). Our findings demonstrate that lowproducing PGE2 (B16/PTGS2 $\Delta$ ) cells led to poor differentiation of immature BM cells into mo-MDSCs and gr-MDSCs. However, following subcutaneous engraftment of B16/PTGS2 $\Delta$ in mice the frequency of intratumoral gr-MDSCs and moMDSCs resulted not modified although tumor growth was significantly reduced. These results suggest that PTGS2, at least in part, contributes to create a favorable milieu for MDSCs accumulation. Chemokines are also considered to play a key role since they promote MDSCs migration into the TME (Umansky et al., 2016). The close interplay among these mediators is demonstrated by the up-regulation of CXCL5 and CXCL8 expression in human non-small cell lung cancer cells and of CXCL1 in colorectal cancer cells induced by PTGS2 (Pold et al., 2004; Wang et al., 2006). CXCL1 is also expressed in $70 \%$ of human melanomas and it is involved in cellular transformation, tumor growth, homing, and metastasis (Dhawan and Richmond, 2002). Our results, demonstrating that CXCL1 serum levels were significantly reduced in B16/ PTGS2 $\Delta$ melanoma bearing mice, are completely in line with these findings and further support the ability of PTGS2 to regulate CXCL1 secretion in melanoma.

Collectively, these findings confirm that PTGS2 is needed to sustain melanoma progression. Indeed, knockdown of ptgs 2 showed remarkable inhibitory effects on tumorigenic property in melanoma cells, including cell proliferation, colony formation capacity, migration, and invasiveness; and modulated immune response by impairing MDSCs differentiation. Finally, ptgs 2 deletion reduces tumor growth and metastasis formation in vivo. Therefore, modulating PTGS2 expression in melanoma cells, perhaps by using genetic engineering like CRISPR technology, could be transformative to improve success rates in the development of new and highly selective drugs for melanoma treatment. 


\section{DATA AVAILABILITY STATEMENT}

All datasets generated for this study are included in the article/ supplementary material.

\section{ETHICS STATEMENT}

The animal study was reviewed and approved by Ministero della Salute Dipartimento per la Sanità Pubblica Veterinaria, la Nutrizione e la Sicurezza degli Alimenti Direzione Generale della Sanità Animale e del Farmaco Veterinario dell'ex Ministero della Salute Ufficio VI - Benessere animale Viale Giorgio Ribotta, 5 EUR Castellaccio 00144 Roma.

\section{REFERENCES}

Becker, M. R., Siegelin, M. D., Rompel, R., Enk, A. H., and Gaiser, T. (2009). COX2 expression in malignant melanoma: a novel prognostic marker? Melanoma Res. 19, 8-16. doi: 10.1097/CMR.0b013e32831d7f52

Behan, F. M., Iorio, F., Picco, G., Goncalves, E., Beaver, C. M., Migliardi, G., et al. (2019). Prioritization of cancer therapeutic targets using CRISPR-Cas9 screens. Nature 568, 511-516. doi: 10.1038/s41586-019-1103-9

Botti, G., Fratangelo, F., Cerrone, M., Liguori, G., Cantile, M., Anniciello, A. M., et al. (2017). COX-2 expression positively correlates with PD-L1 expression in human melanoma cells. J. Transl. Med. 15, 46. doi: 10.1186/s12967-017-1150-7

Bunt, S. K., Sinha, P., Clements, V. K., Leips, J., and Ostrand-Rosenberg, S. (2006). Inflammation induces myeloid-derived suppressor cells that facilitate tumor progression. J. Immunol. 176, 284-290. doi: 10.4049/jimmunol.176.1.284

Bunt, S. K., Yang, L., Sinha, P., Clements, V. K., Leips, J., and Ostrand-Rosenberg, S. (2007). Reduced inflammation in the tumor microenvironment delays the accumulation of myeloid-derived suppressor cells and limits tumor progression. Cancer Res. 67, 10019-10026. doi: 10.1158/0008-5472.CAN-072354

Chapman, P. B., Hauschild, A., Robert, C., Haanen, J. B., Ascierto, P., Larkin, J., et al. (2011). Improved survival with vemurafenib in melanoma with BRAF V600E mutation. N. Engl. J. Med. 364, 2507-2516. doi: 10.1056/ NEJMoa1103782

Crusz, S. M., and Balkwill, F. R. (2015). Inflammation and cancer: advances and new agents. Nat. Rev. Clin. Oncol. 12, 584-596. doi: 10.1038/ nrclinonc.2015.105

De Cicco, P., Panza, E., Ercolano, G., Armogida, C., Sessa, G., Pirozzi, G., et al. (2016). ATB-346, a novel hydrogen sulfide-releasing anti-inflammatory drug, induces apoptosis of human melanoma cells and inhibits melanoma development in vivo. Pharmacol. Res. 114, 67-73. doi: 10.1016/ j.phrs.2016.10.019

Denkert, C., Kobel, M., Berger, S., Siegert, A., Leclere, A., Trefzer, U., et al. (2001). Expression of cyclooxygenase 2 in human malignant melanoma. Cancer Res. 61, 303-308.

Dhawan, P., and Richmond, A. (2002). Role of CXCL1 in tumorigenesis of melanoma. J. Leukoc. Biol. 72, 9-18.

Ezernitchi, A. V., Vaknin, I., Cohen-Daniel, L., Levy, O., Manaster, E., Halabi, A., et al. (2006). TCR zeta down-regulation under chronic inflammation is mediated by myeloid suppressor cells differentially distributed between various lymphatic organs. J. Immunol. 177, 4763-4772. doi: 10.4049/ jimmunol.177.7.4763

Gabrilovich, D. I., and Nagaraj, S. (2009). Myeloid-derived suppressor cells as regulators of the immune system. Nat. Rev. Immunol. 9, 162-174. doi: 10.1038/ nri2506

Garraway, L. A. (2013). Genomics-driven oncology: framework for an emerging paradigm. J. Clin. Oncol. 31, 1806-1814. doi: 10.1200/JCO.2012.46.8934

Goulet, A. C., Einsphar, J. G., Alberts, D. S., Beas, A., Burk, C., Bhattacharyya, A., et al. (2003). Analysis of cyclooxygenase 2 (COX-2) expression during

\section{AUTHOR CONTRIBUTIONS}

GE and PC designed, performed the experiments, analyzed the data and wrote the manuscript. VR performed the flow cytometric experiments. GT and GR supervised the flow cytometric analysis. RC and PK performed bioinformatics analysis. AI provided intellectual contributions, supervised all the experiments, critically revised the manuscript and gave final approval to the publication.

\section{FUNDING}

Funding of this research was provided by the Italian Government grants (PRIN $2012 \mathrm{n}^{\circ}$ : 2012WBSSY4_005).

malignant melanoma progression. Cancer Biol. Ther. 2, 713-718. doi: $10.4161 / \mathrm{cbt} .2 .6 .627$

Guernet, A., and Grumolato, L. (2017). CRISPR/Cas9 editing of the genome for cancer modeling. Methods 121-122, 130-137. doi: 10.1016/j.ymeth.2017.03.007

Hashemi Goradel, N., Najafi, M., Salehi, E., Farhood, B., and Mortezaee, K. (2019). Cyclooxygenase-2 in cancer: a review. J. Cell Physiol. 234, 5683-5699. doi: $10.1002 /$ jcp. 27411

Hauschild, A., Grob, J. J., Demidov, L. V., Jouary, T., Gutzmer, R., Millward, M., et al. (2012). Dabrafenib in BRAF-mutated metastatic melanoma: a multicentre, open-label, phase 3 randomised controlled trial. Lancet 380, 358-365. doi: 10.1016/S0140-6736(12)60868-X

Khair, D. O., Bax, H. J., Mele, S., Crescioli, S., Pellizzari, G., Khiabany, A., et al. (2019). Combining immune checkpoint inhibitors: established and emerging targets and strategies to improve outcomes in melanoma. Front. Immunol. 10, 453. doi: 10.3389/fimmu.2019.00453

Kilkenny, C., Browne, W., Cuthill, I. C., Emerson, M., Altman, D. G., and Group, N. C. R. R. G. W. (2010). Animal research: reporting in vivo experiments: the ARRIVE guidelines. Br. J. Pharmacol. 160, 1577-1579. doi: 10.1111/j.1476-5381.2010.00872.x

Kim, S. H., Roszik, J., Cho, S. N., Ogata, D., Milton, D. R., Peng, W., et al. (2019). The COX2 Effector microsomal PGE2 synthase 1 is a regulator of immunosuppression in Cutaneous Melanoma. Clin. Cancer Res. 25, 16501663. doi: 10.1158/1078-0432.CCR-18-1163

Ko, C. J., Lan, S. W., Lu, Y. C., Cheng, T. S., Lai, P. F., Tsai, C. H., et al. (2017). Inhibition of cyclooxygenase-2-mediated matriptase activation contributes to the suppression of prostate cancer cell motility and metastasis. Oncogene 36, 4597-4609. doi: 10.1038/onc.2017.82

Koike-Yusa, H., Li, Y., Tan, E. P., Velasco-Herrera Mdel, C., and Yusa, K. (2014). Genome-wide recessive genetic screening in mammalian cells with a lentiviral CRISPR-guide RNA library. Nat. Biotechnol. 32, 267-273. doi: 10.1038/nbt.2800

Lee, C., Ramirez, J. A., Guitart, J., and Diaz, L. K. (2008). Expression of cyclooxygenase-2 and peroxisome proliferator-activated receptor gamma during malignant melanoma progression. J. Cutan. Pathol. 35, 989-994. doi: 10.1111/j.1600-0560.2007.00939.x

Martin, M., Wei, H., and Lu, T. (2016). Targeting microenvironment in cancer therapeutics. Oncotarget 7, 52575-52583. doi: 10.18632/oncotarget.9824

Martinez-Lage, M., Puig-Serra, P., Menendez, P., Torres-Ruiz, R., and RodriguezPerales, S. (2018). CRISPR/Cas9 for cancer therapy: hopes and challenges. Biomedicines 6 (4), 105. doi: 10.3390/biomedicines6040105

Menezes, M. E., Talukdar, S., Wechman, S. L., Das, S. K., Emdad, L., Sarkar, D., et al. (2018). Prospects of gene therapy to treat melanoma. Adv. Cancer Res. 138, 213-237. doi: 10.1016/bs.acr.2018.02.007

Meyers, R. M., Bryan, J. G., Mcfarland, J. M., Weir, B. A., Sizemore, A. E., Xu, H., et al. (2017). Computational correction of copy number effect improves specificity of CRISPR-Cas9 essentiality screens in cancer cells. Nat. Genet. 49, 1779-1784. doi: 10.1038/ng.3984

Nakanishi, M., and Rosenberg, D. W. (2013). Multifaceted roles of PGE2 in inflammation and cancer. Semin. Immunopathol. 35, 123-137. doi: 10.1007/ s00281-012-0342-8 
Obermajer, N., Muthuswamy, R., Lesnock, J., Edwards, R. P., and Kalinski, P. (2011). Positive feedback between PGE2 and COX2 redirects the differentiation of human dendritic cells toward stable myeloid-derived suppressor cells. Blood 118, 5498-5505. doi: 10.1182/blood-2011-07-365825

Panza, E., De Cicco,P., Armogida,C. , Scognamiglio, G., Gigantino, V., Botti, G., et al. (2015). Role of the cystathionine gamma lyase/hydrogen sulfide pathway in human melanoma progression. Pigment Cell Melanoma Res. 28, 61-72. doi: 10.1111/pcmr.12312

Panza, E., De Cicco, P., Ercolano, G., Armogida, C., Scognamiglio, G., Anniciello, A. M., et al. (2016). Differential expression of cyclooxygenase-2 in metastatic melanoma affects progression free survival. Oncotarget 7, 57077-57085. doi: 10.18632/oncotarget.10976

Panza, E., Ercolano, G., De Cicco, P., Armogida, C., Scognamiglio, G., Botti, G., et al. (2018). MicroRNA-143-3p inhibits growth and invasiveness of melanoma cells by targeting cyclooxygenase- 2 and inversely correlates with malignant melanoma progression. Biochem. Pharmacol. 156, 52-59. doi: 10.1016/ j.bcp.2018.08.008

Pesic, M., and Greten, F. R. (2016). Inflammation and cancer: tissue regeneration gone awry. Curr. Opin. Cell Biol. 43, 55-61. doi: 10.1016/j.ceb.2016.07.010

Pold, M., Zhu, L. X., Sharma, S., Burdick, M. D., Lin, Y., Lee, P. P., et al. (2004). Cyclooxygenase-2-dependent expression of angiogenic CXC chemokines ENA-78/CXC Ligand (CXCL) 5 and interleukin-8/CXCL8 in human nonsmall cell lung cancer. Cancer Res. 64, 1853-1860. doi: 10.1158/00085472.CAN-03-3262

Revilla, G., Corcoy, R., Moral, A., Escola-Gil, J. C., and Mato, E. (2019). Cross-talk between inflammatory mediators and the epithelial mesenchymal transition process in the development of thyroid carcinoma. Int. J. Mol. Sci. 20 (10), 2466. doi: 10.3390/ijms20102466

Rhodes, D. R., Yu, J., Shanker, K., Deshpande, N., Varambally, R., Ghosh, D., et al. (2004). ONCOMINE: a cancer microarray database and integrated datamining platform. Neoplasia 6, 1-6. doi: 10.1016/S1476-5586(04)80047-2

Robinson, M. D., Mccarthy, D. J., and Smyth, G. K. (2010). edgeR: a Bioconductor package for differential expression analysis of digital gene expression data. Bioinformatics 26, 139-140. doi: 10.1093/bioinformatics/btp616

Roma-Rodrigues, C., Mendes, R., Baptista, P. V., and Fernandes, A. R. (2019). Targeting tumor microenvironment for cancer therapy. Int. J. Mol. Sci. 20 (4), 840. doi: 10.3390/ijms20040840

Schachter, J., Ribas, A., Long, G. V., Arance, A., Grob, J. J., Mortier, L., et al. (2017). Pembrolizumab versus ipilimumab for advanced melanoma: final overall survival results of a multicentre, randomised, open-label phase 3 study (KEYNOTE-006). Lancet 390, 1853-1862. doi: 10.1016/S0140-6736(17) 31601-X

Schadendorf, D., Hodi, F. S., Robert, C., Weber, J. S., Margolin, K., Hamid, O., et al. (2015). Pooled analysis of long-term survival data from phase II and phase III trials of Ipilimumab in unresectable or metastatic melanoma. J. Clin. Oncol. 33, 1889-1894. doi: 10.1016/S0140-6736(17)31601-X

Shain, A. H., Yeh, I., Kovalyshyn, I., Sriharan, A., Talevich, E., Gagnon, A., et al. (2015). The genetic evolution of melanoma from precursor lesions. N. Engl. J. Med. 373, 1926-1936. doi: 10.1056/NEJMoa1502583

Shurin, G. V., Kruglov, O., Ding, F., Lin, Y., Hao, X., Keskinov, A. A., et al. (2019). Melanoma-induced reprogramming of schwann cell signaling aids tumor growth. Cancer Res. 79, 2736-2747. doi: 10.1158/0008-5472.CAN-18-3872

Sinha, P., Clements, V. K., Fulton, A. M., and Ostrand-Rosenberg, S. (2007). Prostaglandin E2 promotes tumor progression by inducing myeloid-derived suppressor cells. Cancer Res. 67, 4507-4513. doi: 10.1158/0008-5472.CAN-064174

Sobolewski, C., Cerella, C., Dicato, M., Ghibelli, L., and Diederich, M. (2010). The role of cyclooxygenase- 2 in cell proliferation and cell death in human malignancies. Int. J. Cell Biol. 2010, 215158. doi: 10.1155/2010/215158

Suarez-Carmona, M., Lesage, J., Cataldo, D., and Gilles, C. (2017). EMT and inflammation: inseparable actors of cancer progression. Mol. Oncol. 11, 805823. doi: 10.1002/1878-0261.12095

Todoric, J., Antonucci, L., and Karin, M. (2016). Targeting Inflammation in cancer prevention and therapy. Cancer Prev. Res. (Phila) 9, 895-905. doi: 10.1158/ 1940-6207.CAPR-16-0209

Topalian, S. L., Sznol, M., Mcdermott, D. F., Kluger, H. M., Carvajal, R. D., Sharfman, W. H., et al. (2014). Survival, durable tumor remission, and longterm safety in patients with advanced melanoma receiving nivolumab. J. Clin. Oncol. 32, 1020-1030. doi: 10.1200/JCO.2013.53.0105

Umansky, V., Blattner, C., Gebhardt, C., and Utikal, J. (2016). The Role of MyeloidDerived Suppressor Cells (MDSC) in Cancer Progression. Vaccines (Basel), p. 4. doi: $10.3390 /$ vaccines4040036

Van Zijl,F., Krupitza, G., and Mikulits, W. (2011). Initial steps of metastasis: cell invasion and endothelial transmigration. Mutat. Res. 728, 23-34. doi: 10.1016/ j.mrrev.2011.05.002

Verma, M. (2012). Personalized medicine and cancer. J. Pers. Med. 2, 1-14. doi: 10.3390/jpm2010001

Viola, J. R., Rafael, D. F., Wagner, E., Besch, R., and Ogris, M. (2013). Gene therapy for advanced melanoma: selective targeting and therapeutic nucleic acids. J. Drug Delivery 2013, 897348. doi: 10.1155/2013/897348

Wang, D., and Dubois, R. N. (2010). The role of COX-2 in intestinal inflammation and colorectal cancer. Oncogene 29, 781-788. doi: 10.1038/onc.2009.421

Wang, D., and Dubois, R. N. (2016). The role of prostaglandin E(2) in tumorassociated immunosuppression. Trends Mol. Med. 22, 1-3. doi: 10.1016/ j.molmed.2015.11.003

Wang, D., Wang, H., Brown, J., Daikoku, T., Ning, W., Shi, Q., et al. (2006). CXCL1 induced by prostaglandin E2 promotes angiogenesis in colorectal cancer. J. Exp. Med. 203, 941-951. doi: 10.1084/jem.20052124

Wesolowski, R., Markowitz, J., and Carson, W. E.3rd (2013). Myeloid derived suppressor cells - a new therapeutic target in the treatment of cancer. J. Immunother. Cancer 1, 10. doi: 10.1186/2051-1426-1-10

Winder, M., and Viros, A. (2018). Mechanisms of drug resistance in melanoma. Handb. Exp. Pharmacol. 249, 91-108. doi: 10.1007/164_2017_17

Youn, J. I., Nagaraj, S., Collazo, M., and Gabrilovich, D. I. (2008). Subsets of myeloid-derived suppressor cells in tumor-bearing mice. J. Immunol. 181, 5791-5802. doi: 10.4049/jimmunol.181.8.5791

Conflict of Interest: The authors declare that the research was conducted in the absence of any commercial or financial relationships that could be construed as a potential conflict of interest.

Copyright (C) 2019 Ercolano, De Cicco, Rubino, Terrazzano, Ruggiero, Carriero, Kunderfranco and Ianaro. This is an open-access article distributed under the terms of the Creative Commons Attribution License (CC BY). The use, distribution or reproduction in other forums is permitted, provided the original author(s) and the copyright owner(s) are credited and that the original publication in this journal is cited, in accordance with accepted academic practice. No use, distribution or reproduction is permitted which does not comply with these terms. 